\title{
Comparison of Supervised and Unsupervised Approaches for Mudstone Lithofacies Classification: Case Studies from the Bakken and Mahantango-Marcellus Shale, USA
}

Shuvajit Bhattacharya ${ }^{1}$, Timothy R. Carr ${ }^{1}$ and Mahesh Pal ${ }^{2}$

${ }^{1}$ West Virginia University, Morgantown, USA; ${ }^{2}$ National Institute of Technology, Kurukshetra, India

\begin{abstract}
Quantitative lithofacies modeling is important to understand the depositional and diagenetic history, and hydrocarbon potential of unconventional resources at a regional scale. The complex heterogeneous nature and large data dimensionality of unconventional mudstone reservoirs increase the challenge of lithofacies interpretation by conventional qualitative methods.
\end{abstract} Quantitative shale lithofacies, which are meaningful, mappable, and predictable at core, well log, and regional scales, can be defined based on mineralogy and Total Organic Carbon (TOC) derived from core analysis and advanced geochemical spectroscopy logs (e.g. Pulsed Neutron Spectroscopy, PNS). However, access to numerous and widespread core samples and geochemical log responses is typically limited by cost and time.

We apply different mathematical techniques to ubiquitous conventional well log suites calibrated to rock types, defined by the limited number of wells with high-quality core and geochemical logs. The documented interrelationships between lithofacies and conventional logs are propagated with a quantified degree of accuracy in wells without advanced log or core data. Our study addresses issues of different approaches of quantitative lithofacies classification and 
prediction techniques from well logs. Various data-driven supervised and unsupervised computational approaches, such as Support Vector Machine (SVM), Artificial Neural Network (ANN), Self-Organizing Map (SOM) and Multi-Resolution Graph-based Clustering (MRGC), are applied and compared to reduce uncertainty of propagating single-well based lithofacies analysis, and efficiently understand geological trends.

Two different dataset from the Devonian Bakken and Mahantango-Marcellus Shale formations in North America are used, in order to undertake a comparative assessment of computational techniques for lithofacies characterization. Original shale lithofacies, defined from geochemical logs and core data, are used to compare the results of selected supervised and unsupervised computational approaches. The results show that both Bakken and Mahantango-Marcellus shale members are vertically and laterally heterogeneous, but can be classified into at least five mudstone lithofacies, along with calcareous siltstone and limestone lithofacies. SVM works better than other techniques for lithofacies classification and prediction in reduced computational time, no iteration, and with highly repeatable results. Accuracy of lithofacies prediction increases if the algorithms are supervised with geological rules.

Keywords: Quantitative modeling, Organic mudstone, Lithofacies, Mineralogy, Well logs, Machine learning

\section{Introduction}

This paper discusses application of different computational techniques in mudstone lithofacies modeling. Lithofacies modeling or assigning a rock type to specific rock samples on the basis of 
petrography or measured physical properties, is fundamental to many subsurface investigations. Even though various clastic and carbonate facies have been studied in detail for depositional and diagenetic environment study, research in mudstone lithofacies is relatively rare. Mudstone is heterogeneous, in terms of variable mineralogy and organic matter content. Two approaches have been followed for mudstone facies modeling. The first approach deals with either single borehole study or descriptive core and outcrop sample analysis (Egenhoff and Fishman, 2013; Schieber, 1999; Singh, 2008), whereas the second approach, which is more recent, is pursued from a quantitative perspective (Bhattacharya et al., 2015; Qi and Carr, 2006; Wang, 2012). In this study we choose two world class Devonian mudstone formations in North America such as the Bakken and Mahantango-Marcellus formations. There have been extensive qualitative studies on mineralogical composition, facies description, and depositional history in both of the shale formations (Egenhoff and Fishman, 2013; Emmanuel and Sonnenberg, 2013; LeFever et al., 2011).

However, it is not always possible to have access to widespread and abundant core, advanced well logs, due to economic and logistic constraints, which poses significant challenges in correct lithofacies interpretation, facies identification, and reservoir characterization. Outcrop shale sample studies can prove to be futile, due to weathering and chance of kerogen degradation over time. Therefore, we emphasize quantitative approaches over qualitative approaches, which contribute to only visual idea about lithology. Quantitative approaches can be used to classify lithofacies using conventional wireline logs at borehole scale, and propagated to multi-well studies to predict lithofacies, and measure accuracy of prediction with available original lithofacies model, derived from core and/or advanced well logs. 
In recent years several mathematical techniques have been proposed for facies and petrophysical property modeling (Al-Anaji and Gates, 2010; Qi and Carr, 2006; Wang et al., 2014). There is also a significant bias to use conventional well log based cutoff values to build facies models quickly. Such deterministic and simplified cutoff values may not work well in complex mudstone formations (Schlanser et al., 2014). In addition, well log cutoff values can be misleading in regional studies, while using them without normalization. Hence, there is a need to compile mathematically powerful machine learning algorithms together, to assess their individual capacity for predictive lithofacies modeling, and define a protocol for using them in specific geological scenarios. We claim that a few quantitative techniques can learn complex subsurface geological pattern better than others.

This paper compares different mathematical methods to classify and predict mudstone lithofacies from ubiquitous conventional well logs, in terms of reducing uncertainty in exploration. Different supervised and unsupervised machine learning algorithms including Support Vector Machine (SVM), Artificial Neural Network (ANN), Self-Organizing Map (SOM), and Multi Resolution Graph-based Clustering (MRGC) are used and discussed in detail, with corresponding advantages and disadvantages, to design a suitable schematic workflow for intelligent mudstone lithofacies pattern recognition. We first introduce mathematical principles of all four algorithms, followed by actual lithofacies characteristics in the dataset, and then use them to classify and predict lithofacies. The result shows that both Bakken and MahantangoMarcellus shale members are heterogeneous, but can be classified into at least five mudstone lithofacies, along with calcareous siltstone and limestone lithofacies. Supervised approaches, 
especially SVM, work better than other techniques for lithofacies classification and prediction purposes in reduced computational time, no iteration, and with highly repeatable results.

\section{Principles of Mathematical Algorithms}

\subsection{Support Vector Machine (SVM)}

SVM is one of the fastest growing approaches of computational intelligence, in terms of data classification and prediction in all scientific disciplines. It is based on solid mathematical background of statistical learning theory (Kordon, 2010; Vapnik, 1995).

The idea behind SVM is to map the original data from input space to a higher dimensional or even infinite-dimensional feature space so that distance between each data points gets increased, and classification among different variables into different clusters becomes simpler (Luts et al., 2010). The mapping is done by a suitable choice of kernel function.

The key feature of SVM is support vectors (Fig. 1). Support vectors are the data points (i.e. samples), which lie on the boundaries of different classes (such as different lithofacies) during classification. There can be a large number of hyperplanes, which can discriminate between two classes, out of which SVM tries to find the optimal hyperplane, which is the farthest from both classes. For two-class problems, it assumes two planes that support each class, and maximizes the distance (called margin) between them. Optimization problem involves pushing these parallel planes apart until they collide with data points, representative of each class (called support vectors). Therefore, SVM uses a significantly small portion of the training dataset (Pal and Foody, 2012). 


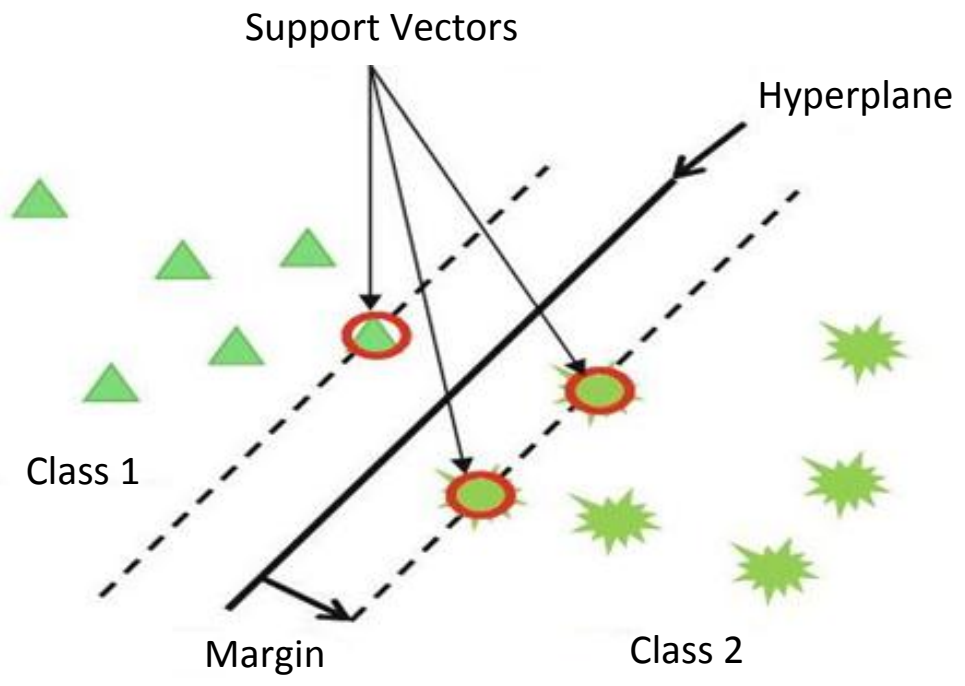

Fig. 1. An optimal hyperplane separating two classes of data in SVM model (Kordon, 2010)

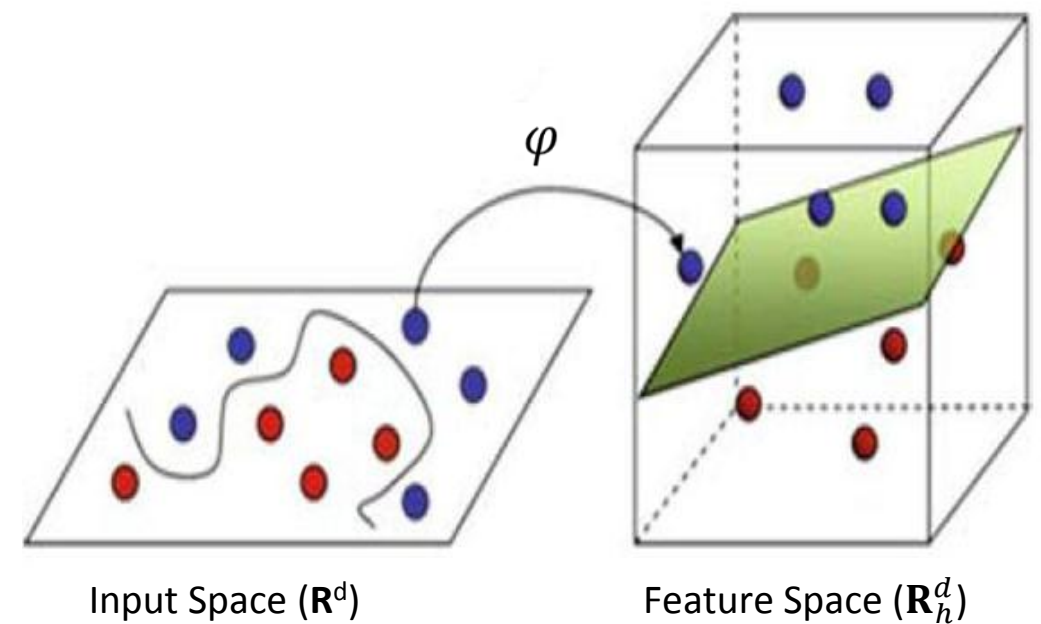

Fig. 2. SVM kernel function maps data from input space to feature space (modified after Kordon, 2010)

Consider a training dataset $\left\{x_{i}, y_{i}\right\}_{i=1}^{N}$, with $\mathrm{x}_{\mathrm{i}} \in \mathbf{R}^{\mathrm{d}}$ being the input vectors and $\mathrm{y}_{\mathrm{i}} \in\{-1,+1\}$ the class labels. SVM maps the input vector $\mathrm{x}$ from the input space to $\mathrm{d}^{\text {h}}$-dimensional feature space using a function $\varphi():. \mathbf{R}^{\mathrm{d}} \rightarrow \mathbf{R}_{h}^{d}$ (Fig. 2). The separating hyperplane or classification function (indicator function) in the feature space is defined as

$\mathrm{w}^{\top} \varphi(\mathrm{x})+\mathrm{b}=0$ 
where $b \in \mathbf{R}$. Parameters $b$ and $w$ determine the offset from origin, and the orientation of discriminating plane respectively. A data point $x$ is assigned to the class 1 (or lithofacies 1 ) if $f(x)$ $=\operatorname{sign}\left(w^{\top} \varphi(x)+b\right) \geq+1$ or to class 2 (or lithofacies 2 ) if $f(x) \leq-1$.

However, in most of the real cases, perfect linear separation is impossible due to overlapping classes, especially in geology, which is why a restricted number of misclassifications are tolerated around the margin. The resulting optimization problem for SVM is written as

$\min _{\mathrm{w}, \mathrm{b}, \xi_{1}, \ldots \xi_{k}}\left[\frac{1}{2}\|\mathrm{w}\|^{2}+\mathrm{C} \sum_{\mathrm{i}=1}^{\mathrm{n}} \xi_{\mathrm{i}}\right]$

such that $y_{i}\left(w^{\top} \varphi(x)+b\right) \geq 1-\xi_{i}, \quad i=1, \ldots \ldots, n$

$\xi_{i} \geq 0, i=1, \ldots \ldots, n$ where $C$ is a positive regularization constant (or penalty parameter).

The first term in the above equation corresponds to minimization of the quadratic program to maximize the margin, and the second term relates to empirical error or penalty (Kecman, 2005; Luts et al., 2010). Larger C assigns a higher penalty to errors.

In case of non-linear data modeling, SVM maps data to a significantly large feature space to make them linearly separable and it uses a kernel functions to solve the optimization problem in that space. Four type of kernel functions are generally used: linear, polynomial, Radial Basis Function (RBF), and multilayer perceptron (Cortes and Vapnik, 1995; Tan et al., 2015; Wang et al., 2014).

Although originally built as a binary classifier, SVM algorithm can be used in multi-class geological pattern recognition problems. SVM handles the multi-class problems efficiently by one-againstall and pairwise comparison (one-against-one) techniques (Hastie and Tibshiranu, 1998; Li et al., 
2003). Pairwise comparison method leads to larger number of simpler binary classification, compared to one-against-all method (Wang et al., 2014).

\subsection{Artificial Neural Network (ANN)}

ANN is a popular machine learning algorithm, which is used extensively in data classification and prediction studies (Bishop, 1995). ANN attempts to mimic some of the basic information processing methods in human brain (Kordon, 2010; McCulloh and Pitts, 1943).

Generally, ANN consists of three layers: input layer, hidden layer and output layer, all of which are connected via artificial neurons (Fig. 3). The input layer receives the incoming data, which is distributed to the hidden layer. Hidden layer is the key part of the ANN structure that learns data structure, in terms of patterns and interrelationship among input variables, and then distributes the learned data patterns (mathematically expressed as weight) to the output layer. The output of a node is controlled by an activation function, which is basically a function of total input parameters and a threshold, which determines the initiation of output (Doveton, 1994). 




Fig. 3. Schematic architecture of an ANN algorithm where input layer corresponds to different well logs and output refers to different lithofacies (modified after Manshad et al., 2015)

ANN modeling starts with randomly assigned weight coefficients. Then a set of data patterns is fed forward repeatedly and the weights of the neurons are modified until the output matches closely with the actual values (Doveton, 1994). Training is usually accomplished by "backpropagation technique" in iterative manner, while minimizing the error between ANN computed output and target output.

There are several parameters to control, while designing ANN such as number of hidden layers, number of hidden layer nodes, learning rate, damping coefficient or momentum, and number of iterations for better optimization.

\subsection{Self-Organizing Map (SOM)}

SOM was first introduced by Kohonen $(1982,2001)$, as a technique for clustering and reduction of data dimensionality. SOM clusters data in such a way that the statistical relationship among 
multidimensional input dataset is converted to a lower dimensional SOM grid space without losing topological properties among data points (Roy, 2013). SOM is different from ANN, in the sense that the former preserves geometrical relationships of input data (Venkatesan and Mullai, 2014).

Consider a 2D SOM represented by PV (prototype vectors) $m_{i}, m_{i}=\left[m_{i 1}, m_{i 2}, \ldots, m_{i N}\right]$, where $N$ represents dimensions of prototype vectors. After arranging the PVs in a lower-dimensional 2D grid space, SOM model is trained and tested with an available dataset.

During SOM training process, an input vector $(\mathrm{x})$ is randomly chosen from a set of input vectors, then the Euclidean distance between this vector and all other vectors $\left(m_{i}, i=1,2, . ., n\right)$ are computed. According to Kohonen (2001), the prototype vector $\left(\mathrm{m}_{\mathrm{b}}\right)$, with minimum distance from the input vector, is called the Best Matching Unit (BMU), which can be expressed as:

$\left\|x-m_{b}\right\|=\min \left\{\left\|x-m_{i}\right\|\right\}$

Then, the BMU prototype vector $m_{b}$, and other input vectors within a neighborhood radius of $\sigma$ are updated as a part of the training. The rule of updating the weight of prototype vectors inside and outside the neighborhood radius is given by (Kohonen, 2001; Roy, 2013)

$$
\begin{aligned}
m_{i}(t+1) & =m_{i}(t)+\alpha(t) h_{b i}(t)\left[x-m_{i}(t)\right] & \text { if }\left\|r_{i}-r_{b}\right\| \leq \sigma(t) \\
& =m_{i}(t) & \text { if }\left\|r_{i}-r_{b}\right\|>\sigma(t)
\end{aligned}
$$

where $r_{b}$ and $r_{i}$ are position vectors of $m_{b}$ and $m_{i}$ respectively. The neighborhood function is defined as $h_{b i}(t)$ where $t$ represents the length of training. The neighborhood radius decreases with successive iteration and BMUs are brought closer to the input vectors, finally forming different clusters. Next, the trained prototype vectors are color coded for better visualization of various clusters. 


\subsection{Multi Resolution Graph-based Clustering (MRGC)}

MRGC is an unsupervised data classification technique, which can solve the dimensionality problem and obtain valuable information about the input dataset (Ye and Rabiller, 2000). It is based on K-nearest neighbor and graph based presentation. Most of the other techniques require exact number of clusters prior to training, whereas MRGC automatically clusters the data, and yet allows the user to either lump or subdivide different clusters based on "ground truth" at the end.

MRGC describes data pattern by two indices: Neighboring Index (NI) and Kernel Representative Index (KRI). NI measures how close the data points are with respect to each other in the input domain. It is computed by mutual rank of neighboring data points, which can be expressed as

$$
\begin{aligned}
N I(x) & =\exp (-m / \alpha) \\
& =1 \text { if } m=0 \\
& \cong 0 \text { otherwise }
\end{aligned}
$$

Here $\mathrm{x}$ is the $\mathrm{m}^{\text {th }}$ nearest neighbor of $\mathrm{y}$, which is $\mathrm{n}^{\text {th }}$ nearest neighbor of $\mathrm{x}$ in the dataset, $m \leq$ $N-1$, and $\alpha>0$.

However, it is important to recognize optimal number of clusters, otherwise infinite number of clusters can be constructed, including local irregularities, which is not correct. Hence, the other index KRI measures the probability of each data point to be a representative cluster kernel (Ye and Rabiller, 2000). KRI can be expressed as

$\operatorname{KRI}(x)=N I(x) M(x, y) D(x, y)$, where $M(x, y)=M$ if $y$ is the $m^{\text {th }}$ neighbor of $x$, and $D(x, y)$ is the distance between $\mathrm{x}$ and $\mathrm{y}$. Data points corresponding to the highest KRI values are assigned to form final clusters or lithofacies. 


\section{Bakken and Mahantango-Marcellus Shale Lithofacies}

We chose the Devonian Bakken and Marcellus formations in North America to apply, and compare different quantitative techniques for mudstone lithofacies modeling. Both Bakken and Marcellus formations are big unconventional oil and gas plays in North America. The Bakken Formation in the Williston basin spans over portions of North Dakota, South Dakota, Montana, and extends in to Canada, whereas the Mahantango-Marcellus formations in the Appalachian basin is present in West Virginia, Pennsylvania, and New York etc. in the United States (Fig. 4).

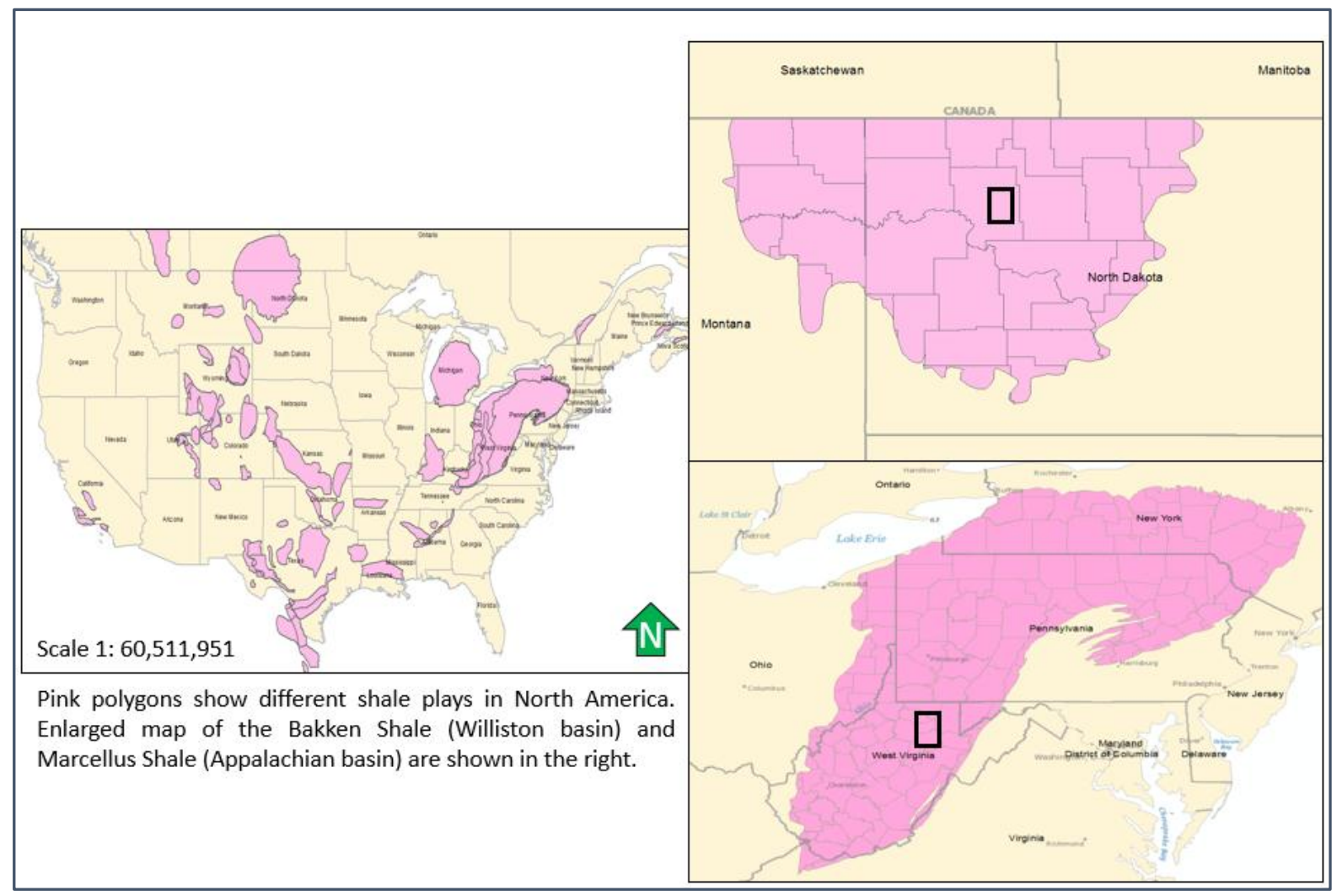

Fig. 4. Study areas in the Williston and Appalachian basins marked by black rectangles

The Bakken Formation consists of two world class source rocks (upper Bakken and lower Bakken shale) that sandwich the middle Bakken member, which is composed of mixed lithologies, 
including sandstone, dolostone and limestone. The Mahantango-Marcellus interval is composed of gray shale and organic rich shale units with carbonate interlayers.

Original shale lithofacies models, based on core geochemical data (XRD and TOC) and advanced PNS logs, are available for the Bakken and Mahantango-Marcellus mudstone intervals (Bhattacharya et al., 2015; Wang, 2012). Both shale members are heterogeneous; they are rich in quartz and clay, compared to carbonate (Fig. 5).

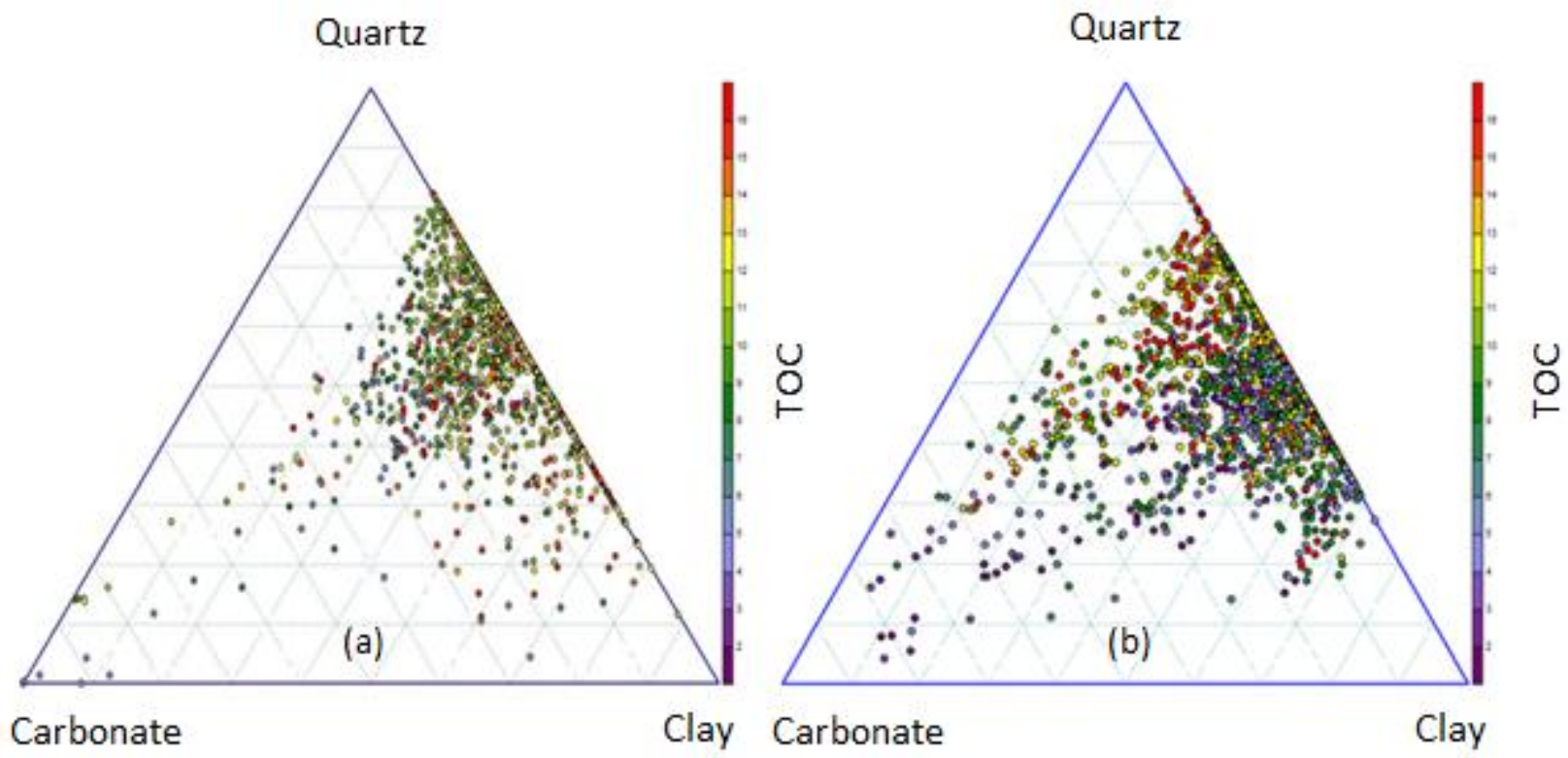

Fig. 5. Ternary diagrams ( $a$ and $b$ ) showing variation in major mineralogy and TOC content (all in percentage) in the Bakken and Marcellus shale formations respectively. Both shale formations are siliceous mudstone.

We apply a schematic methodology to classify the shale lithofacies in a quantitative manner (Bhattacharya and Carr, 2016). We use three criteria such as clay volume, TOC content, and quartz-to-carbonate ratio to classify different lithofacies (Fig. 6). We use clay volume of $30 \%$ in the Bakken dataset, whereas $40 \%$ cutoff is used in the Mahantango-Marcellus dataset, calibrated to core-based ground truth information. Both Bakken and Mahantango-Marcellus shale members are composed of at least five different lithofacies such as Organic Mudstone (OMD), 
Organic Siliceous Shale (OSS), Gray Mudstone (GMD), Gray Siliceous Shale (GSS), and Gray Mixed Shale (GMS), along with limestone and mixed lithology (calcareous siltstone). Organic Mixed Shale lithofacies is absent from the available dataset, however, the schematic methodology can be used to evaluate other mudstone formations. The non-shaly middle Bakken member is composed of mixed lithology (siltstone, dolostone, and limestone), which is considered as a single lithofacies unit for the scope of this study. OSS lithofacies has high silica and high organic matter content, which make it amenable to effective hydraulic stimulation and hydrocarbon production. Fig. 7 and Fig. 8 show depth displays of various conventional well logs, mineralogical analysis, and original lithofacies model in the Bakken and Mahantango-Marcellus intervals.

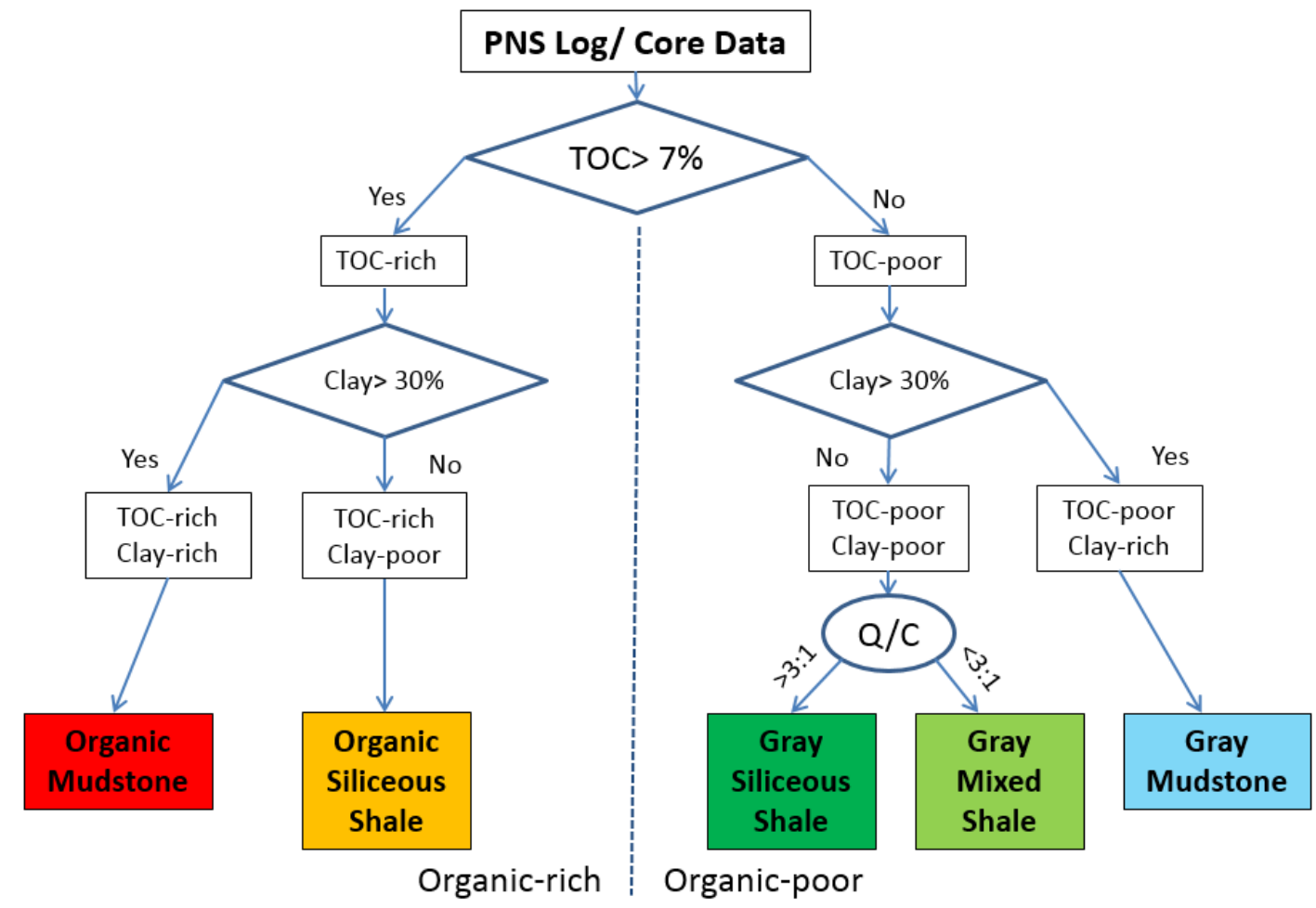

Fig. 6. Schematic methodology to classify shale lithofacies. Three criteria such as clay volume, TOC content, and quartz-to-carbonate ratio $(\mathrm{Q} / \mathrm{C})$ are used to classify shale lithofacies quantitatively (modified after Bhattacharya and Carr, 2016). 


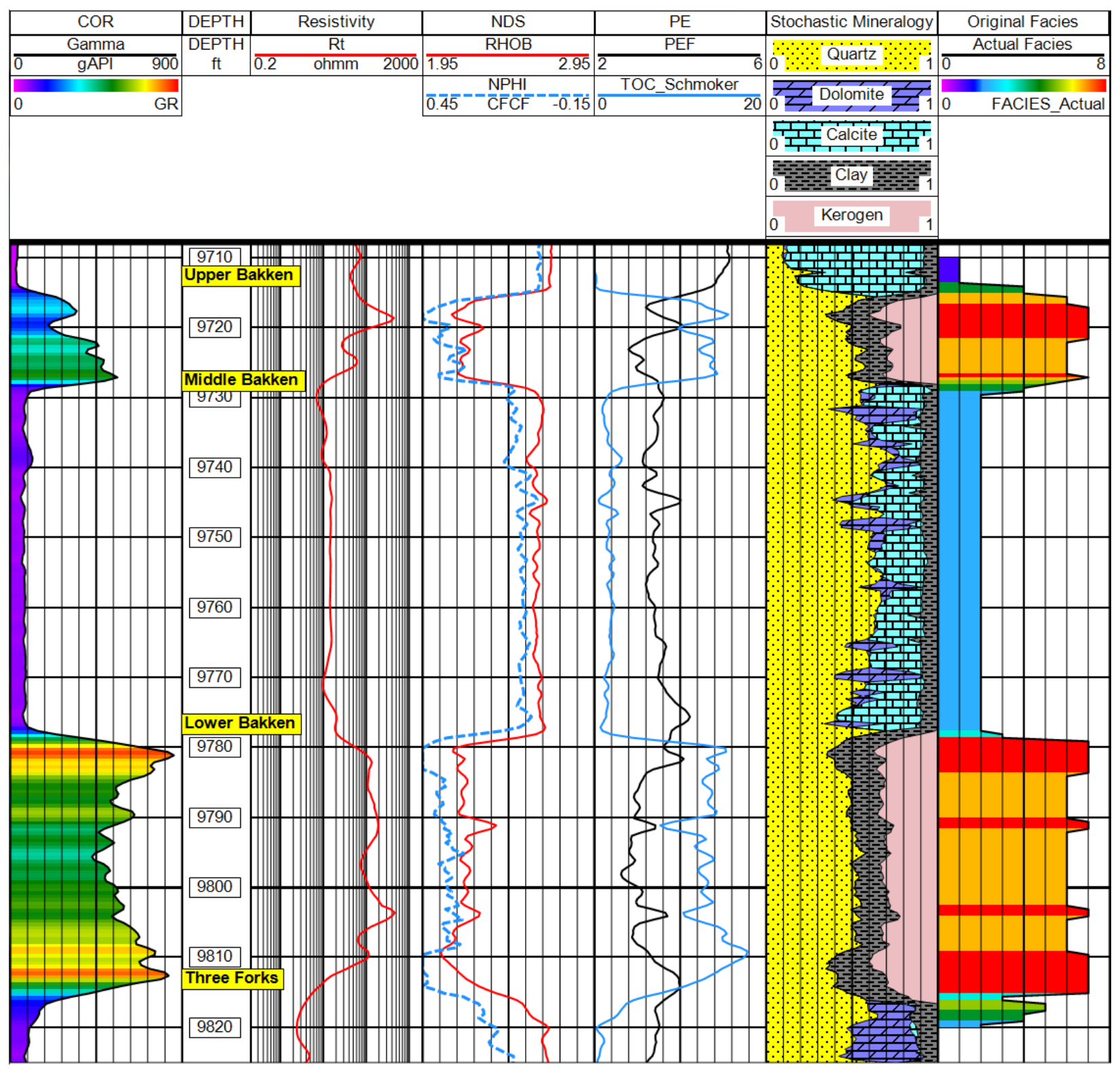

Fig. 7. Integrated well log and original lithofacies model display in one of the training wells in the Bakken dataset. Upper Bakken and lower Bakken shale members are composed five different mudstone lithofacies, based on mineralogy and organic matter richness. Limestone, mixed lithology (calcareous siltstone), GMD, GMS, GSS, OSS, and OMD lithofacies are represented by numerical codes from 1 to 7 in a rainbow pattern. 


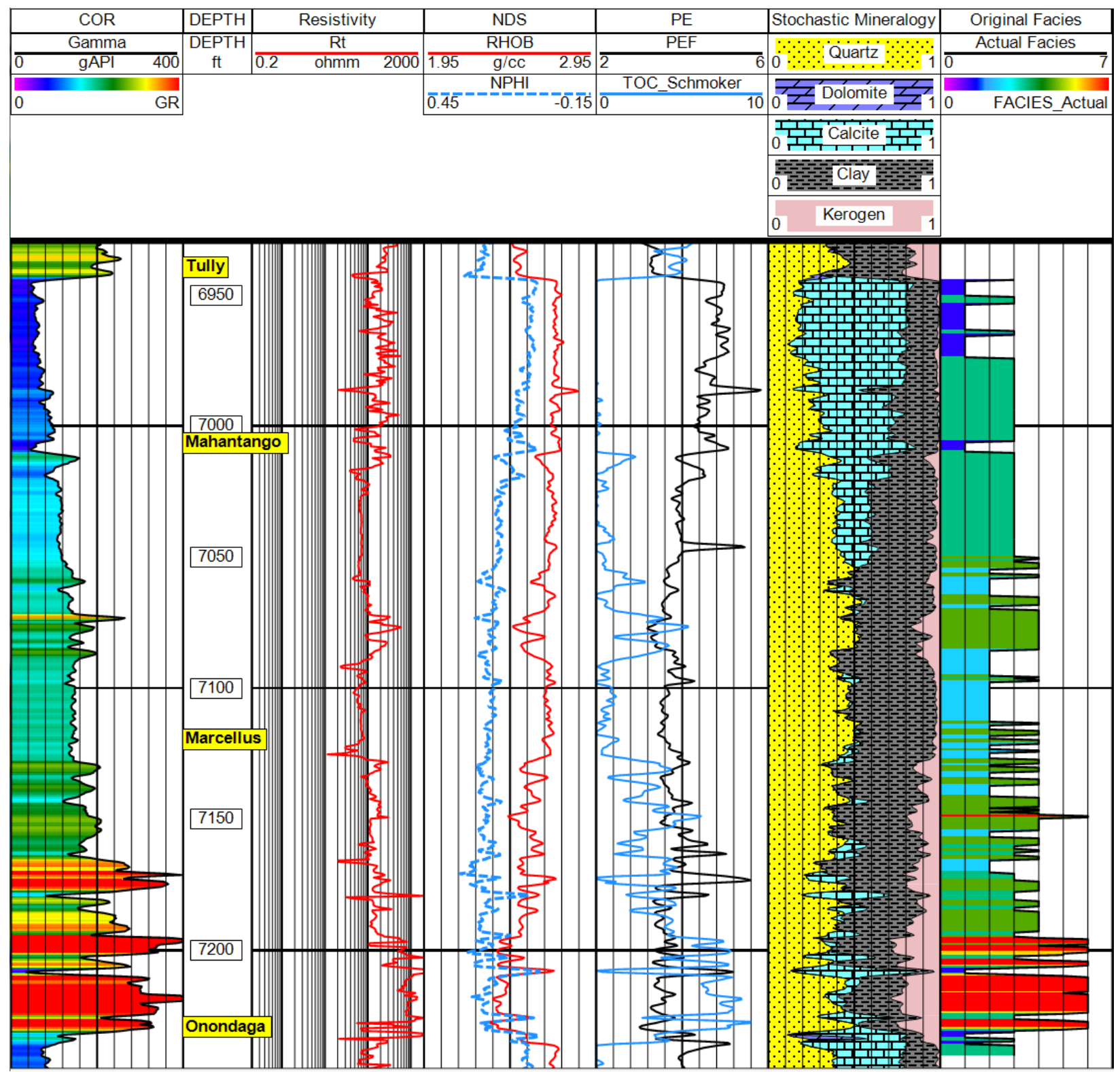

Fig. 8. Integrated well log and original lithofacies model display in one of the training wells in the MahantangoMarcellus interval. The Mahantango interval is mostly composed of lower order gray shale facies, whereas the Marcellus Formation is mostly composed of different types of organic shale lithofacies, along with carbonate interlayers.

\section{Materials and Methods}


Two different dataset containing conventional well log suites, such as gamma, resistivity, neutron porosity, density, and photoelectric factors, are compiled from the Devonian Bakken and Mahantango-Marcellus shale formations, in order to undertake a comparative assessment of computational techniques for lithofacies characterization. The Bakken dataset consists of petrophysical logs from three wells, whereas the dataset from the Mahantango-Marcellus interval contains similar data from two wells. In general, the petrophysical log data are obtained from around 100 feet (30.48 meters) thick Bakken interval, whereas the data interval is of around 200 feet (60.96 meters) in the Mahantango-Marcellus formations. Each well log is recorded at half-foot (0.15 meters) increment.

We compare, and investigate the capabilities of all four quantitative algorithms (SVM, ANN, SOM, and MRGC) in shale lithofacies classification and prediction, using well logs from the Bakken and Mahantango-Marcellus Shale formations as examples. The emphasis of the assessment is on the potential for value creation in subsurface geologic analysis by reducing uncertainties in lithofacies pattern recognition. The whole methodology includes: (1) pre-processing input petrophysical dataset; and (2) training and testing the classifiers for lithofacies modeling.

\subsection{Pre-processing Input Petrophysical Dataset}

Pre-processing input petrophysical logs is an important step to construct a reliable lithofacies model. This process involves proper selection of well logs, which are facies-sensitive. Apart from that, well logs should be normalized and environmentally corrected based on regional geology. For example, resistivity logs should be corrected for hydrocarbon effects, sonic log should be free from overburden related compression effects near basin center, and neutron porosity logs 
should be free from clay bound-water effects, so that facies models generated with these logs will be independent of any fluid and normalization related issues.

We choose five conventional well logs such as gamma (GR), natural logarithm of deep resistivity (LnRt), neutron porosity (NPHI), bulk density (RHOB), and photoelectric factor (PEF), and five other derived parameters such as apparent matrix density (RHOmaa), photoelectric absorption index (Umaa), gamma/density (GR/RHOB), photoelectric/density (PEF/RHOB), and TOC as input for lithofacies modeling (Fig. 9). Shale lithofacies modeling is a multi-class problem; it is better to use more input parameters to increase the average distance between data points, thereby forming easily separable lithofacies clusters. GR, LnRt, and RHOB logs are used as input petrophysical parameters, because organic shale has higher uranium concentration (associated with high GR), higher resistivity, and lower density, compared to organic-poor lithofacies. NPHI log is used as it can help to distinguish clay-rich intervals from clay-poor intervals, whereas PEF log is utilized to separate carbonate and non-carbonate layers. Other parameters such as RHOmaa, Umaa, GR/RHOB, and PEF/RHOB are utilized to enhance the evaluation of high silica content in the shale formations, detect carbonate interlayers, and remove parts of the noise if any. TOC parameter is used as a quantitative measure of kerogen richness in the mudrocks, which can distinguish organic-rich shale from organic-poor gray shale. Kerogen has low density ( 1.1 g/cc). TOC is derived from RHOB log using Schmoker's method (1983).

TOC $=(154.497 / \mathrm{RHOB})-57.261$

RHOmaa $=($ RHOB $-\mathrm{PHIA}) /(1-\mathrm{PHIA})$

Umaa $=(P E F *$ RHOB $-0.5 *$ PHIA $) /(1-P H I A)$

where PHIA corresponds to average porosity from NPHI and RHOB logs. 

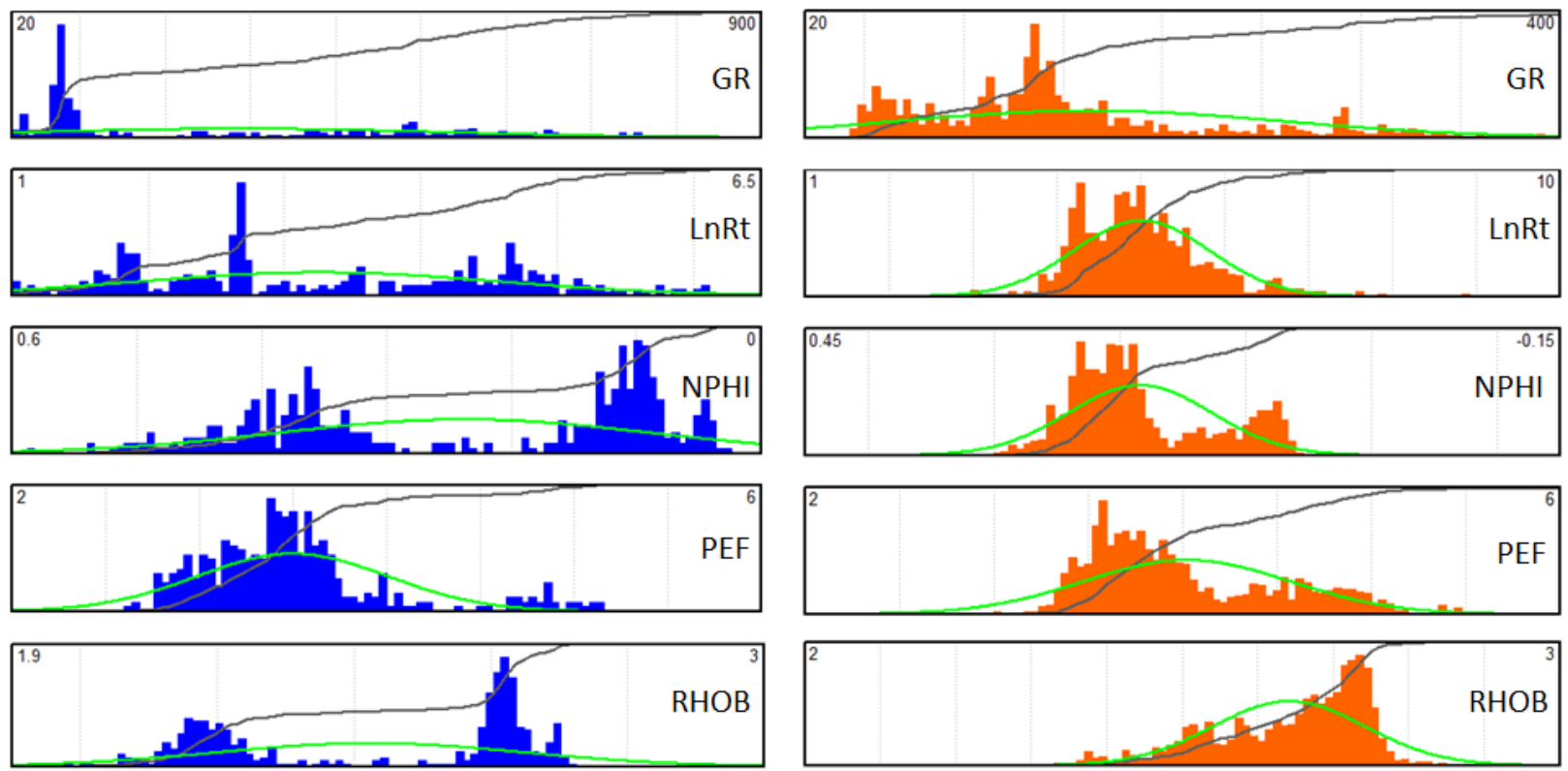

(a)

(b)

Fig. 9. Histograms showing statistical feature of conventional well log suites (as model input) in the Bakken (a) and Mahantango-Marcellus (b) dataset. The green curve indicates Gaussian distribution and the black curve indicates cumulative distribution.

\subsection{Training and Testing the Classifiers}

All three machine learning algorithms (SVM, ANN, and SOM) need to be set up with optimum network parameters to enable them work efficiently for lithofacies training and testing. A large number of trials with various combination of user-defined parameters are performed to train the classifiers. Geolog ${ }^{\mathrm{TM}}$ and WEKA programs are used to train and test petrophysical dataset, and PowerLog ${ }^{\mathrm{TM}}$ to display well logs and lithofacies model. We used an Intel computer with $32 \mathrm{~GB}$ RAM and CPU@3.6 GHz for this study.

For SVM classifier, choice of kernel function is significantly important. Literature review in different research areas suggests that RBF function performs quite well in comparison to other 
kernels (Camps-Valls, 2009; Hsu et al., 2003), and hence used in this study. RBF kernel based SVM classifier requires fine tuning of two user-defined parameters: gamma (kernel parameter), and penalty parameter (C).

We apply back propagation ANN algorithm with one hidden layer with both datasets. Optimal values of learning rate, momentum, and epoch (i.e. number of iterations) obtained after large number of trials is used for enhanced petrophysical data classification and testing. In case of SOM, we use 2D SOM method, with square grid of neurons (five in each side).

In case of Bakken dataset, SVM, ANN and SOM algorithms are trained and tested on dataset obtained from different wells for facies prediction. Whereas, a 10-fold cross-validation is used with the Marcellus dataset, due to smaller sample size. With unsupervised MRGC method, first a number of clusters are formed to generate a high-resolution lithofacies model, which is then lumped into a coarser model based on similarity of data statistics in different clusters, and the original lithofacies model. Results from SVM, ANN and SOM are represented in form of confusion matrices and overall classification accuracy.

\section{Results and Discussion}

Results from both Bakken and Mahantango-Marcellus dataset show that SVM method is the best lithofacies classifier in training and testing domains. This performance is attributed to the RBF kernel. Application of RBF function in the SVM classifier generated best possible result. Because, RBF kernel can efficiently map non-linear data to a higher-dimension feature space, and solve the problem of data classification. 
In the Bakken dataset SVM accuracy of data prediction is $87.3 \%$, compared to ANN (83.7\%), SOM (84.03\%), and MRGC (71.3\%), shown in the confusion matrices (Tables 1, 2, 3 and 4). The best values of gamma and $C$ in the SVM model are found to be 1.2 and 25 respectively. The optimum values of learning rate and momentum in the ANN algorithm are 0.3 and 0.8 respectively. For 2D SOM a lower dimensional square grid $(5 \times 5)$ is chosen (Fig. 10). In case of MRGC, first a highresolution lithofacies model is built up with 16 clusters, which is then lumped into relatively coarser resolution lithofacies model of seven classes to match with the original lithofacies model.

\section{Table 1}

Confusion matrix illustrates accuracy of SVM algorithm in lithofacies prediction in the Bakken test dataset. Overall accuracy by SVM is $87.3 \%$.

\begin{tabular}{|c|c|c|c|c|c|c|c|c|}
\cline { 2 - 9 } \multicolumn{1}{c|}{} & \multicolumn{7}{c|}{ Actual } \\
\cline { 2 - 9 } & Lithofacies & 1 & 2 & 3 & 4 & 5 & 6 & 7 \\
\hline \multirow{5}{*}{ Predicted } & 1 & 25 & 3 & 0 & 0 & 0 & 0 & 0 \\
\cline { 2 - 10 } & 2 & 0 & 140 & 0 & 3 & 2 & 0 & 0 \\
\cline { 2 - 9 } & 3 & 0 & 0 & 6 & 0 & 2 & 1 & 1 \\
\cline { 2 - 9 } & 4 & 1 & 0 & 0 & 1 & 3 & 0 & 0 \\
\cline { 2 - 10 } & 5 & 0 & 0 & 0 & 0 & 1 & 0 & 0 \\
\cline { 2 - 10 } & 7 & 0 & 0 & 0 & 0 & 0 & 0 & 50 \\
\cline { 2 - 10 } & Absolute & $96.15 \%$ & $97.90 \%$ & $100 \%$ & $25 \%$ & $12.50 \%$ & $97.82 \%$ & $67.60 \%$ \\
\hline
\end{tabular}

\section{Table 2}

Confusion matrix illustrates accuracy of ANN algorithm in lithofacies prediction in the Bakken test dataset. Overall accuracy by ANN is $83.7 \%$. 


\begin{tabular}{|c|c|c|c|c|c|c|c|c|}
\cline { 2 - 9 } \multicolumn{1}{c|}{} & \multicolumn{7}{c|}{} & \multicolumn{7}{c|}{ Actual } \\
\cline { 2 - 9 } & Lithofacies & 1 & 2 & 3 & 4 & 5 & 6 & 7 \\
\hline \multirow{5}{*}{ Predicted } & 1 & 23 & 0 & 0 & 0 & 0 & 0 & 0 \\
\cline { 2 - 10 } & 2 & 2 & 125 & 1 & 1 & 2 & 0 & 0 \\
\cline { 2 - 10 } & 3 & 1 & 13 & 2 & 1 & 1 & 0 & 0 \\
\cline { 2 - 10 } & 4 & 0 & 5 & 1 & 2 & 1 & 0 & 0 \\
\cline { 2 - 10 } & 5 & 0 & 0 & 2 & 0 & 4 & 1 & 0 \\
\cline { 2 - 10 } & 7 & 0 & 0 & 0 & 0 & 0 & 1 & 57 \\
\cline { 2 - 10 } & Absolute & $88.46 \%$ & $87.41 \%$ & $33 \%$ & $50 \%$ & $50.00 \%$ & $95.65 \%$ & $77.03 \%$ \\
\hline
\end{tabular}

Table 3 Confusion matrix illustrates accuracy of 2D SOM algorithm in lithofacies prediction in the Bakken test dataset. Overall accuracy by SOM is $84.03 \%$.

\begin{tabular}{|c|c|c|c|c|c|c|c|c|}
\cline { 2 - 9 } \multicolumn{1}{c|}{} & \multicolumn{9}{c|}{} & \multicolumn{7}{c|}{ Actual } \\
\cline { 2 - 9 } & Lithofacies & 1 & 2 & 3 & 4 & 5 & 6 & 7 \\
\hline \multirow{5}{*}{ Predicted } & 1 & 26 & 5 & 0 & 0 & 1 & 0 & 0 \\
\cline { 2 - 10 } & 2 & 0 & 138 & 0 & 4 & 5 & 0 & 0 \\
\cline { 2 - 9 } & 3 & 0 & 0 & 0 & 0 & 1 & 0 & 0 \\
\cline { 2 - 10 } & 4 & 0 & 0 & 0 & 0 & 0 & 0 & 0 \\
\cline { 2 - 10 } & 5 & 0 & 0 & 6 & 0 & 1 & 1 & 6 \\
\cline { 2 - 10 } & 7 & 0 & 0 & 0 & 0 & 0 & 4 & 52 \\
\cline { 2 - 10 } & Absolute & $100.00 \%$ & $96.50 \%$ & $0 \%$ & $0 \%$ & $0 \%$ & $89.13 \%$ & $70.27 \%$ \\
\hline
\end{tabular}

Table 4 Confusion matrix illustrates accuracy of MRGC algorithm in lithofacies prediction in the Bakken test dataset. Overall accuracy by MRGC is $71.3 \%$. 


\begin{tabular}{|c|c|c|c|c|c|c|c|c|}
\hline & & \multicolumn{7}{|c|}{ Actual } \\
\hline & Lithofacies & 1 & 2 & 3 & 4 & 5 & 6 & 7 \\
\hline \multirow{8}{*}{ Predicted } & 1 & 26 & 4 & 0 & 0 & 1 & 0 & 0 \\
\hline & 2 & 0 & 98 & 0 & 0 & 3 & 0 & 0 \\
\hline & 3 & 0 & 33 & 0 & 1 & 0 & 0 & 0 \\
\hline & 4 & 0 & 8 & 0 & 0 & 0 & 0 & 0 \\
\hline & 5 & 0 & 0 & 6 & 3 & 4 & 1 & 2 \\
\hline & 6 & 0 & 0 & 0 & 0 & 0 & 38 & 19 \\
\hline & 7 & 0 & 0 & 0 & 0 & 0 & 7 & 53 \\
\hline & $\begin{array}{l}\text { Absolute } \\
\text { Accuracy }\end{array}$ & $100.00 \%$ & $68.53 \%$ & $0 \%$ & $0 \%$ & $50.00 \%$ & $82.60 \%$ & $71.62 \%$ \\
\hline
\end{tabular}

Fig. 11 and Fig. 12 show visual comparison of four different facies models, with respect to the original lithofacies model during training and testing phases. It appears that all four algorithms can be trained to understand the well log data pattern associated with lithofacies distribution significantly well, however, most of them fail to predict lithofacies accurately during testing.


(a) 

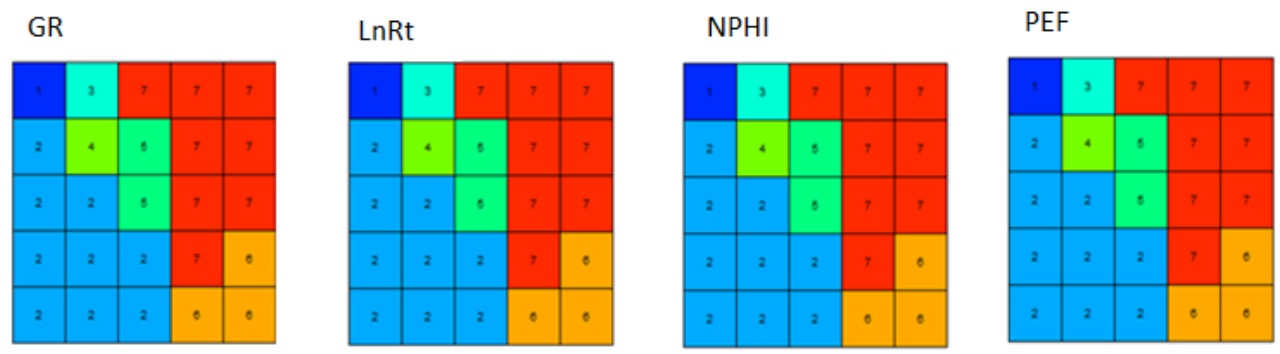

RHOB
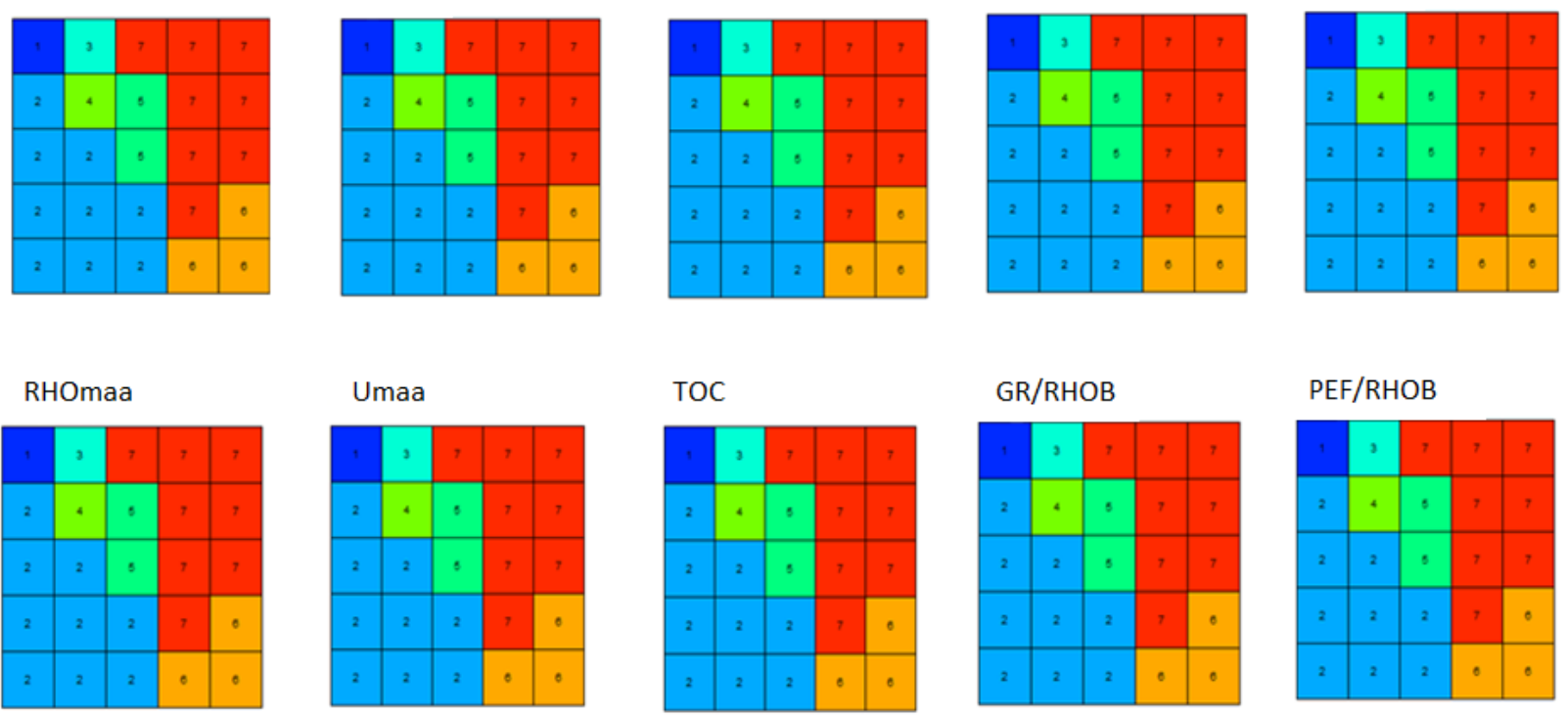

(b)

Fig. 10. An example of 2D SOM maps representing all ten input parameters in lower-dimensional grid space (five neurons in each side) by representative log values (a) and lithofacies (b) respectively in the Bakken dataset 


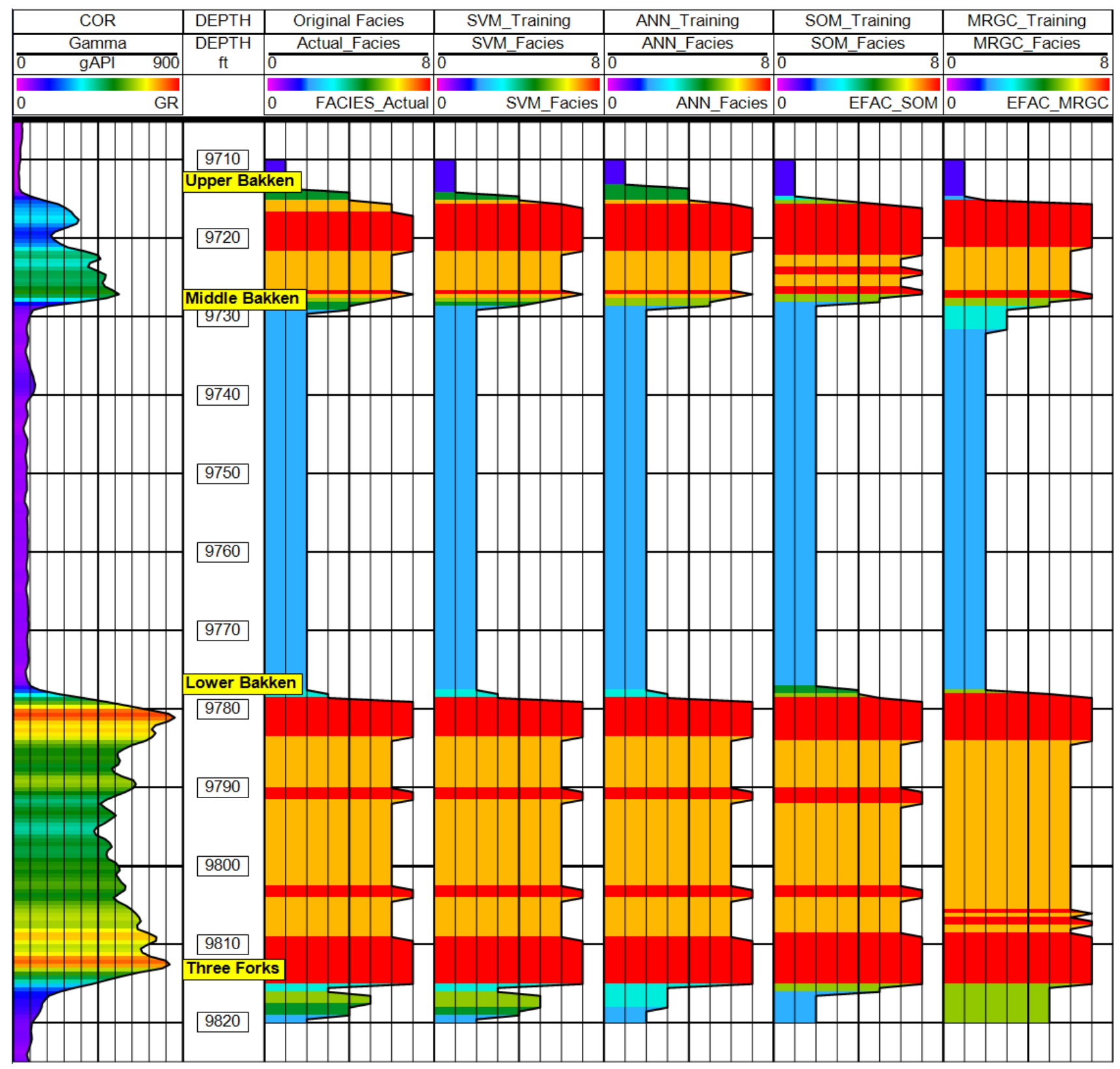

Fig. 11. The Bakken interval lithofacies are classified in a training well. The second track shows original lithofacies, and third, fourth, fifth, and sixth track are showing training results from four different algorithms. Lithofacies models classified by all three supervised techniques (SVM, ANN, and SOM) look significantly similar to the original lithofacies model. 




Fig. 12. The Bakken interval lithofacies are classified in a test well. The second track shows original lithofacies, and four other tracks showing predicted lithofacies results from four different algorithms.

In the Marcellus dataset, SVM achieves accuracy of $82.46 \%$ for lithofacies classification, which is much higher than that of ANN (78.75\%), SOM (69.65\%), and MRGC (64.42\%). The optimal values of gamma (i.e. 4.1) and C (i.e. 20) are used with SVM classifier with this dataset. The optimal parameters used with ANN and SOM are found to be the same as used in the Bakken dataset. In 
case of MRGC, first a high-resolution lithofacies model is built up with 18 clusters, which is then merged to six classes, matching with the original lithofacies model. A comparative assessment of all four quantitative techniques is shown in Fig. 13 and confusion matrices (Tables 5, 6, 7 and 8).

Fig. 14 summarizes lithofacies prediction results by four algorithms in both dataset.



Fig. 13. The Mahantango-Marcellus interval lithofacies are predicted in a test well. The second track shows original lithofacies, and third, fourth, fifth, and sixth tracks show test results from four different algorithms. 
Table 5 Confusion matrix illustrates accuracy of SVM algorithm in lithofacies prediction in the MahantangoMarcellus dataset. Overall accuracy by SVM is $82.46 \%$.

\begin{tabular}{|c|c|c|c|c|c|c|c|}
\hline & \multirow[b]{3}{*}{ Lithofacies } & \multirow{2}{*}{\multicolumn{6}{|c|}{ Actual }} \\
\hline & & & & & & & \\
\hline & & 1 & 2 & 3 & 4 & 5 & 6 \\
\hline \multirow{7}{*}{ Predicted } & 1 & 56 & 0 & 12 & 0 & 0 & 0 \\
\hline & 2 & 0 & 106 & 2 & 32 & 0 & 0 \\
\hline & 3 & 11 & 7 & 181 & 9 & 1 & 0 \\
\hline & 4 & 0 & 8 & 12 & 99 & 0 & 1 \\
\hline & 5 & 0 & 0 & 0 & 0 & 1 & 2 \\
\hline & 6 & 0 & 0 & 0 & 1 & 6 & 46 \\
\hline & $\begin{array}{l}\text { Absolute } \\
\text { Accuracy }\end{array}$ & $83.58 \%$ & $87.60 \%$ & $87.44 \%$ & $70.21 \%$ & $12.50 \%$ & $93.88 \%$ \\
\hline
\end{tabular}

Table 6 Confusion matrix illustrates accuracy of ANN algorithm in lithofacies prediction in the MahantangoMarcellus dataset. Overall accuracy by ANN is $78.75 \%$.

\begin{tabular}{|c|c|c|c|c|c|c|c|}
\hline & \multirow[b]{2}{*}{ Lithofacies } & \multicolumn{6}{|c|}{ Actual } \\
\hline & & 1 & 2 & 3 & 4 & 5 & 6 \\
\hline \multirow{7}{*}{ Predicted } & 1 & 57 & 0 & 12 & 0 & 0 & 0 \\
\hline & 2 & 0 & 101 & 4 & 36 & 0 & 0 \\
\hline & 3 & 10 & 7 & 173 & 18 & 0 & 0 \\
\hline & 4 & 0 & 13 & 18 & 85 & 0 & 0 \\
\hline & 5 & 0 & 0 & 0 & 0 & 2 & 0 \\
\hline & 6 & 0 & 0 & 0 & 2 & 6 & 49 \\
\hline & $\begin{array}{l}\text { Absolute } \\
\text { Accuracy }\end{array}$ & $85.07 \%$ & $83.47 \%$ & $83.57 \%$ & $60.28 \%$ & $25.00 \%$ & $100.00 \%$ \\
\hline
\end{tabular}

Table 7 Confusion matrix illustrates accuracy of 2D SOM algorithm in lithofacies prediction in the MahantangoMarcellus dataset. Overall accuracy by SOM is $69.64 \%$. 


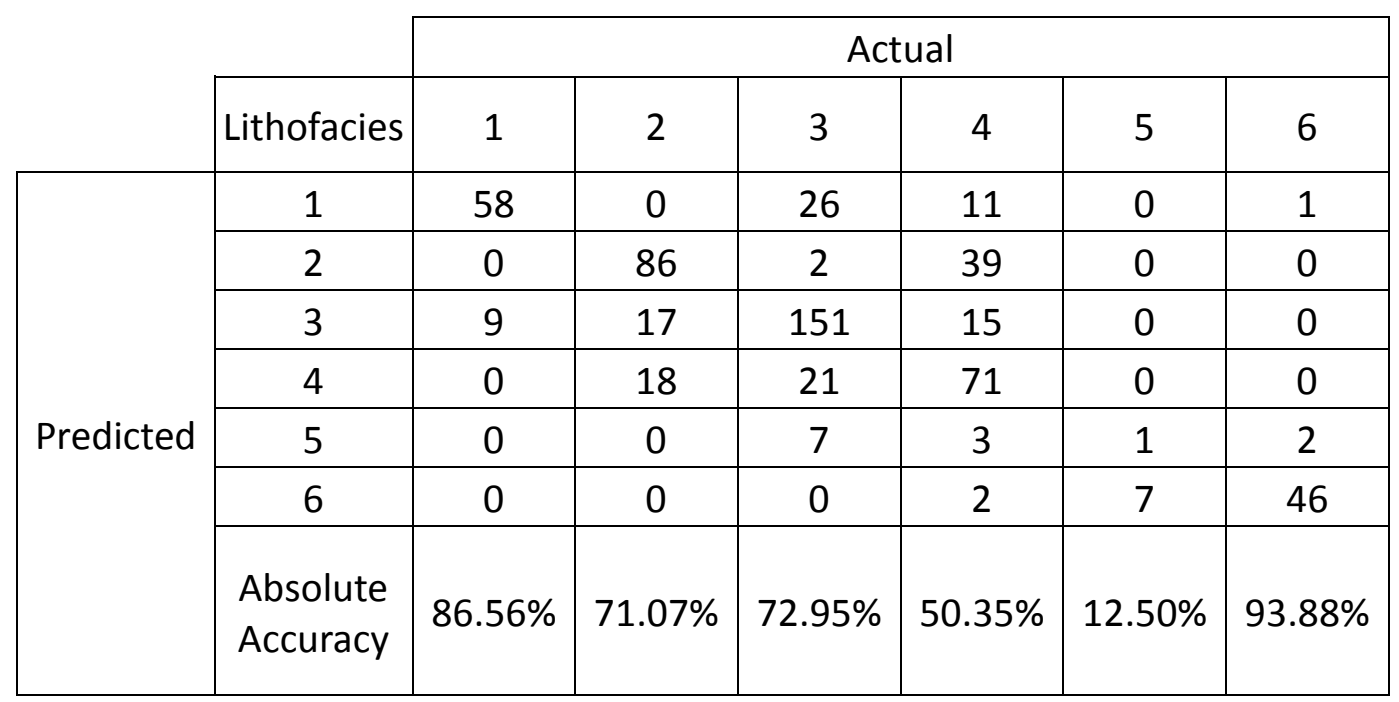

Table 8 Confusion matrix illustrates accuracy of MRGC algorithm in lithofacies prediction in the MahantangoMarcellus dataset. Overall accuracy by MRGC is $64.42 \%$.

\begin{tabular}{|c|c|c|c|c|c|c|c|}
\hline & \multirow[b]{2}{*}{ Lithofacies } & \multicolumn{6}{|c|}{ Actual } \\
\hline & & 1 & 2 & 3 & 4 & 5 & 6 \\
\hline \multirow{7}{*}{ Predicted } & 1 & 58 & 0 & 36 & 0 & 0 & 0 \\
\hline & 2 & 0 & 104 & 16 & 61 & 0 & 0 \\
\hline & 3 & 1 & 5 & 118 & 5 & 0 & 0 \\
\hline & 4 & 6 & 12 & 26 & 70 & 0 & 2 \\
\hline & 5 & 2 & 0 & 11 & 5 & 5 & 20 \\
\hline & 6 & 0 & 0 & 0 & 0 & 3 & 27 \\
\hline & $\begin{array}{l}\text { Absolute } \\
\text { Accuracy }\end{array}$ & $86.56 \%$ & $85.95 \%$ & $57.00 \%$ & $49.65 \%$ & $62.50 \%$ & $55.10 \%$ \\
\hline
\end{tabular}




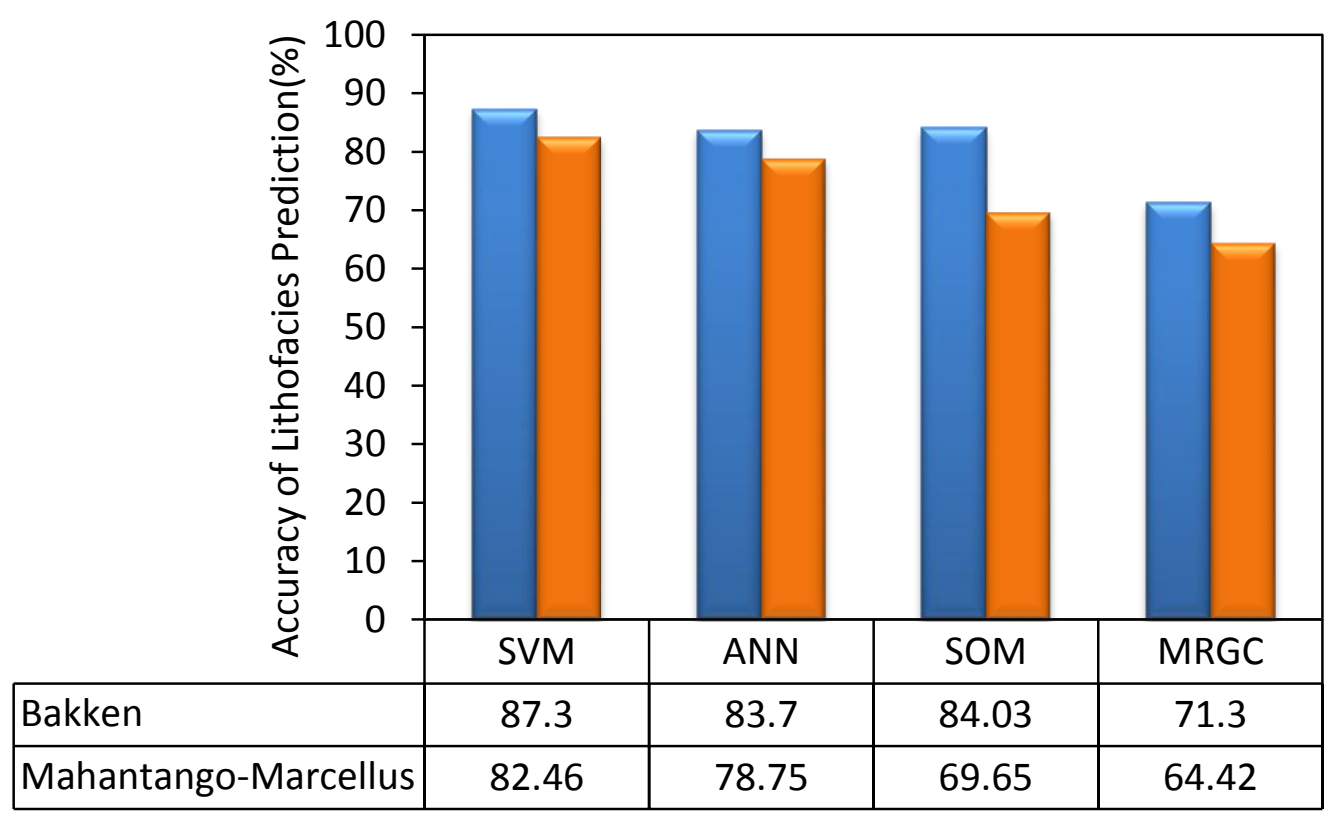

Bakken $\square$ Mahantango-Marcellus

Fig. 14. Summary of lithofacies prediction by SVM, ANN, SOM and MRGC methods in the Bakken and MahantangoMarcellus dataset. SVM appears to be the best method.

Both Bakken and Mahantango-Marcellus shale members are vertically and laterally heterogeneous, but can be classified into five different mudstone lithofacies, along with calcareous siltstone and limestone units. All supervised algorithms can train and test shale lithofacies patterns. However, the overall uncertainty of each method mostly stems from relatively poor sample proportion of the gray shale lithofacies (GMD, GMS, and GSS). Results from both dataset indicate that SVM works far better than other techniques for lithofacies classification and prediction purposes in reduced computational time $(0.11 \mathrm{sec}$ and $0.18 \mathrm{sec}$ with the Bakken and Mahantango-Marcellus dataset, in comparison to $5.58 \mathrm{sec}$ and $2.38 \mathrm{sec}$ respectively by ANN algorithm), requires no iteration, and with highly repeatable results with the same dataset, because it does not require setting of randomized interconnected weights as 
opposed to ANN algorithm. SVM also uses a significantly small portion of training data represented by support vectors compared to all other approaches, which require full training dataset during training. With the Bakken dataset, SVM uses 40 support vectors, whereas it needs only 26 support vectors to represent the full petrophysical data pattern associated with lithofacies in the Marcellus dataset. Further, SVM needs only two parameters (gamma and C) to optimize during training and testing. Fig. 15 shows that accuracy of lithofacies classification approaches $100 \%$ by increasing values of gamma and C during training. In fact, SVM training models start mimicking the original lithofacies model, once gamma and C values are over 100. But the models fail to work successfully outside their training domain, with such high gamma and C parameters, due to the loss of its generalization property. Relatively low values of gamma and C help to balance the model during training and testing.


Fig. 15. SVM Network parameter optimization by checking accuracy level at every gamma and C values (a and b). In terms of computational cost used by SOM and MRGC algorithms (both of them take more than 120 sec per well to generate lithofacies models), their precise values of the computational costs cannot be exactly compared with SVM and ANN algorithms, because SOM and MRGC algorithms 
were implemented using different programming languages and software. Nevertheless, a comparison of computational cost suggests that the SVM is computationally less demanding than the ANN, SOM, and MRGC.

Fig. 16 shows changes in accuracy of SVM based lithofacies classification with increasing size of the training dataset. For the Bakken interval, 4 training dataset of varying size (i.e. 157, 235, 313, and 391 samples for all seven lithofacies) were generated, using stratified random sampling (DeGroot and Starr, 1969). Stratified random sampling was used, because the original dataset is highly imbalanced, which implies proportions of all seven lithofacies are not the same. Bakken test dataset consisting of 307 samples was used with different training dataset. Results from Fig. 15 suggest that the performance of SVM classifier depends on the size of the training samples for lithofacies classification, which confirms the findings of Sebtosheikh and Salehi (2015), suggesting increase in classification accuracy with increasing training sample size. These results are also similar to other studies (Pal and Foody, 2010; Pal and Mather, 2005).

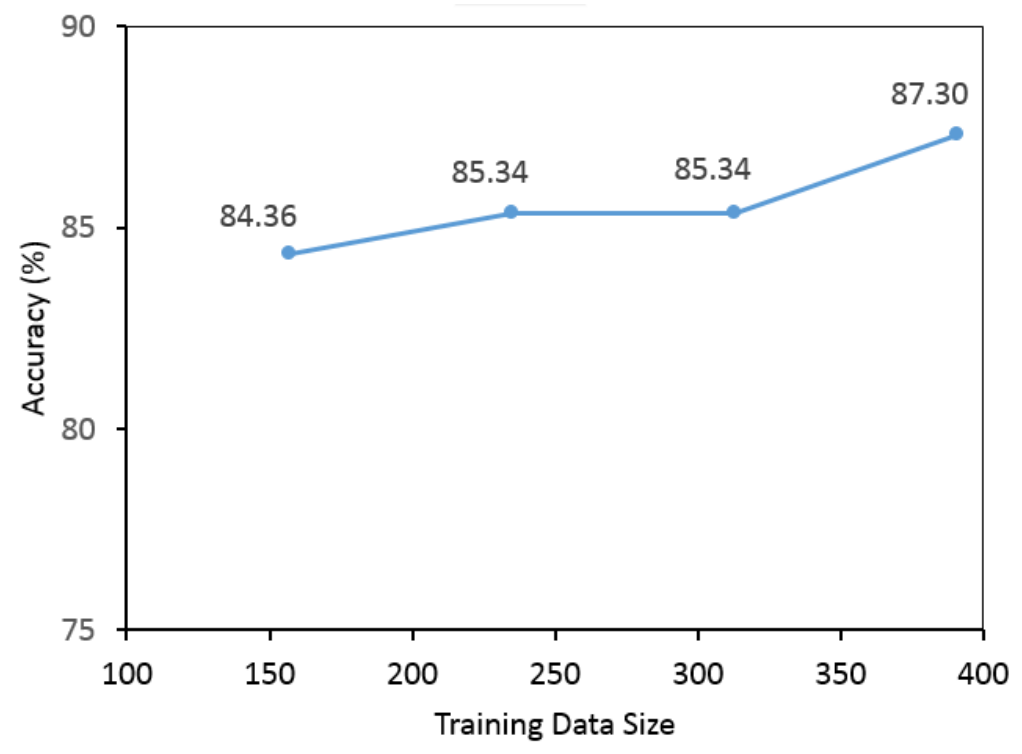

Fig. 16. Variation in lithofacies classification accuracies with change in data size 
Although, ANN and SOM methods produced good results, they work as black-box model. The lower accuracy of these supervised algorithms, compared to SVM, can be attributed to local minima problem. Number of iterations for these algorithms in the both dataset is set at the range of 1000 to 2000 to derive a global solution, rather than a solution stuck in local minima error. However, this process is not cost-effective (time). Number of iterations also depends on the complexity and size of dataset. Moreover, there are several user defined data dependent parameters required to control during ANN model building process; such as number of hidden layers, learning rate, and momentum, which are data dependent. MRGC is a powerful tool, which can reveal natural data structure, without interpreter's bias. The lower rate of accurate prediction by MRGC with these datasets may result from high error rates resulting from the small sample size of relatively rare lithofacies such as inorganic gray shale lithofacies or even suboptimum input well log conditioning. The probability of predicting relatively rare lithofacies in the sample population increases, if the data is intelligently partitioned rather than random splitting for cross-validation, so at least a few samples of each lithofacies are present during training, testing, and validation phases.

We recommend using MRGC as an exploratory technique if the geology is unknown, and then use the initially generated lithofacies model as a reference for SVM based lithofacies classification. MRGC helps to understand high-resolution natural data structure, which can be used to understand the complex lithofacies pattern. Once, the lithofacies pattern is established and/or calibrated to "ground truth" information at various scales of analysis, SVM algorithm can be used efficiently for lithofacies modeling in other test wells.

\section{Conclusions}


The study shows that heterogeneous and complex mudstone lithofacies can be modeled by pattern recognition tools. These kinds of machine-learning tools are useful to classify and predict lithofacies in wells, with limited a priori geological knowledge. Once lithofacies model is defined in each well in the study area, they can be populated in grids to create 3D geocellular facies models, providing insight to depositional and diagenetic processes. The major conclusions of this study are as follows:

1. Both Bakken and Mahantango-Marcellus shale members are heterogeneous, but can be classified into at least five mudstone lithofacies, along with calcareous siltstone and limestone lithofacies.

2. Apart from fundamental working principles, the uncertainty of each method (SVM, ANN, SOM, and MRGC) also depends on the size, complexity of the dataset, and suitable choice of input parameters for lithofacies classification.

3. SVM is the best method for lithofacies classification and prediction purposes in reduced computational resources, no iteration, and with highly repeatable results.

4. Accuracy of lithofacies prediction increases with geological rules being superimposed.

5. The probability of predicting relatively rare facies in the sample population is increased if the data is intelligently partitioned, rather than random splitting, so at least a few samples from each lithofacies are present during training and testing processes.

\section{Acknowledgements}

We would like to thank Julie LeFever of North Dakota Geological Survey and PDC Energy for providing access to well log database. We would also like to express our thanks to CGG Jason 
(PowerLog ${ }^{\mathrm{TM}}$ ), IHS (Petra ${ }^{\mathrm{TM}}$ ), and Paradigm (Geolog ${ }^{\mathrm{TM}}$ ) for providing necessary software facilities at West Virginia University. The authors wish to thank three reviewers, whose comments help to strengthen the manuscript.

\section{References}

Al-Anazi, A., Gates, I.D., 2010. On the capability of Support Vector Machines to Classify Lithology from Well Logs, Natural Resources Research, 19 (2), 125-139.

Al-Anazi, A., Gates, I.D., 2010. A support vector machine algorithm to classify lithofacies and model permeability in heterogeneous reservoirs, Engineering Geology, 114, 267-277.

Bishop C.M., 1995. Neural Networks for Pattern Recognition, New York, Oxford University Press. Bhattacharya, S., Carr, T., Wang, G., 2015. Shale Lithofacies Classification and Modeling: Case Studies from the Bakken and Marcellus Formations, North America, presented at AAPG Annual Convention and Exhibition, Search and Discovery \#90216, June 1.

Bhattacharya, S., Carr, T.R., 2016. Integrated Petrofacies Characterization and Interpretation of Depositional Environment of the Bakken Shale in the Williston Basin, North America, Petrophysics, 57(2), 96-111.

Camps-Valls, Gustavo, and Lorenzo Bruzzone, 2009. Kernel methods for Remote Sensing Data Analysis, John Wiley \& Sons.

Christianini, C., Shawe-Taylor, J., 2000. An introduction to support vector machines and other kernel-based learning methods, Cambridge, Cambridge University Press.

Cortes, C., Vapnik, V., 1995. Support vector networks, Mach. Learn., 20, 273-297. 
DeGroot M.H., Starr, N., 1969. Optimal Two-stage Stratified Sampling, The Annals of Mathematical Statistics, 40 (2), 575-582.

Doveton, J.H., 1994. Geologic Log Analysis Using Computer Methods, Tulsa, AAPG Computer Publications in Geology, 2.

Egenhoff, S.O., Fishman, N.S., 2013. Traces in the dark-sedimentary processes and facies gradients in the Upper Shale Member of the Upper Devonian-Lower Mississippian Bakken Formation, Williston basin, North Dakota, U.S.A, Journal of Sedimentary Research, 83.

Emmanuel, O.O., Sonnenberg, S.A., 2013. Concepts and Methods for the Recognition of Cyclicity in the Marcellus Shale of the Appalachian Basin, NE USA, presented at the Unconventional Resources Technology Conference, URTeC 1563723, August 12-14.

Hall, M., Frank, E., Holmes, G., Pfahringer, B., Reutemann, P., Witten, I.H., 2009. The WEKA Data Mining Software: An Update; SIGKDD Explorations, 11 (1), 10-18.

Hastie, T., Tibshirani, R., 1998. Classification by pairwise coupling. Ann. Stat, 26(2), 451-471.

Hsu, C.W., Chih-Chung C., Chih-Jen L., 2003. A Practical Guide to Support Vector Classification, Technical report, Department of Computer Science, National Taiwan University.

Kecman, V., 2005. Support Vector Machines -an introduction. In: Wang, L., (Ed.), Support Vector Machines: Theory and Applications, Chap 1. Springer-Verlag, Berlin Heidelberg, pp. 1-47.

Kohonen, T., 1982. Self-organized formation of topologically correct feature maps, Biological Cybernetics, 43, 59-69. 
Kohonen, T., 2001. Self-organizing Maps, $3^{\text {rd }}$ ed., Berlin Heidelberg, Springer-Verlag.

Kordon, A.K., 2010. Applying Computational Intelligence: How to Create Value, Berlin Heidelberg, Springer-Verlag.

LeFever, J. A., LeFever, R.D., Nordeng, S.H., 2011. Revised nomenclature for the Bakken Formation (Mississippian- Devonian), North Dakota, In: Robinson, J.W., LeFever, J.A., Gaswirth, S.B., eds., The Bakken-Three Forks Petroleum System in the Williston Basin: Denver, Colo., Rocky Mountain Association of Geologists, pp. 11-26.

Li, T., Zhu, S., Ogihara, M., 2003. Using discriminant analysis for multi-class classification: An experimental investigation,. In: Proceedings of the Third IEEE International Conference on Data Mining, pp 589-592.

Luts, J., Ojeda, F., Plas, R.V., Moor, B.D., Huffel, S.V., Suykens, J.A.K., 2010. A tutorial on support vector machine-based methods for classification problems on chemometrics, Analytica Chimica Acta, 665, 129-145.

Manshad, A.K., Rostami, H., Rezaei, H., Hosseini, S.M., 2015. Application of Artificial Neural Network- Particle Swarm Optimization Algorithm for Prediction of Asphaltene Precipitation during Gas Injection Process and Comparison with Gaussian Process Algorithm, Journal of Energy Resources Technology, 137, $1-5$.

McCulloch, W., Pitts, W., 1943. A logical calculus of the ideas immanent in nervous activity, Bulletin of Mathematical Biophysics, 7, $115-133$. 
Pal, M., Mathur, P.M., 2006. Some issues in the classification of DAIS hyperspectral data, International Journal of Remote Sensing 27 (14), 2895-2916.

Pal, M., Foody G.M., 2010. Feature selection for classification of hyperspectral data by SVM,

IEEE Transactions on Geoscience and Remote Sensing, 48 (5), 2297-2307.

Pal, M., Foody, G.M., 2012. Evaluation of SVM, RVM and SMLR for accurate image classification with limited ground data, IEEE Journal of Selected Topics in Applied Earth Observations and Remote Sensing, 5 (5), 1344-1355.

Qi, L.S., Carr, T.R., 2006. Neural network prediction of carbonate lithofacies from well logs, Big Bow and Sand Arroyo Creek fields, Southwest Kansas, Computers \& Geosciences, 32, 947-964.

Roy, A., 2013. Latent Space Classification of Seismic Facies, Ph. D Dissertation, University of Oklahoma, Norman, Oklahoma.

Schieber, J., 1999. Distribution and deposition of mudstone facies in the Upper Devonian Sonyea Group of New York: Journal of Sedimentary Research, 69, 909-925.

Schlanser, K., Grana, D., Campbell-Stone, E., 2014. Petro-elastic facies classification in the Marcellus Shale by applying Expectation Maximization to measured well logs, presented at SEG Annual Meeting (DOI http://dx.doi.org/10.1190/segam2014-0939.1).

Schmoker, J.W., Hester, T.C., 1983. Organic carbon in Bakken Formation, United States portion of Williston Basin: American Association of Petroleum Geologists, Bulletin, 67, 2165-2174. 
Sebtosheikh, M. A., Salehi, A., 2015. Lithology prediction by support vector classifiers using inverted seismic attributes data and petrophysical logs as a new approach and investigation of training data set size effect on its performance in a heterogeneous carbonate reservoir, Journal of Petroleum Science and Engineering, 134, 143-149.

Singh, P., 2008. Llithofacies and sequence stratigraphic framework of the Barnett Shale, northeast Texas, Ph. D Dissertation, University of Oklahoma, Norman, Oklahoma.

Tan, M.J., Liu, Q., Zhang, S.Y., 2013. A dynamic adaptive radial basis function approach for total organic carbon content prediction in organic shale, Geophysics, 78 (6), 445-459.

Wang, G., 2012. Black shale lithofacies prediction and distribution pattern analysis of Middle Devonian Marcellus shale in The Appalachian basin, northeastern U.S.A., Ph.D. Dissertation, West Virginia University, Morgantown, West Virginia.

Wang G., Carr, T.R., Ju, Y., Li, C., 2014. Identifying organic-rich Marcellus Shale Lithofacies by support vector machine classifier in the Appalachian basin, Computers \& Geosciences, 64, 52-60. Vapnik, V., 1995. The nature of Statistical Learning Theory, New York, Springer.

Venkatesan, P., Mullai, M., 2014. Visualization of Breast Cancer Data by SOM Component Planes, International Journal of Science and Technology, 3(2), 127-131.

Ye, Shin-Ju, Rabiller, P., 2000. A new tool for electro-facies analysis: multi-resolution graph-based clustering, presented at SPWLA 41 ${ }^{\text {st }}$ Annual Logging Symposium, June 4- 7. 